\title{
Las biografías criminales de David Viñas
}

\author{
David Viñas’ Criminal Biographies
}

\begin{abstract}
Román Setton
Universidad de Buenos Aires, Facultad de Filosofía y Letras, Departamento de Letras; Universidad del Cine; Buenos Aires, Argentina. Correo electrónico: rsetton@hotmail.com
\end{abstract}

Con el seudónimo de Pedro Pago, David Viñas escribió al comienzo de su carrera como narrador tres novelas sobre bandidos célebres argentinos: Chicho Grande, Chicho Chico y Mate Cocido. Publicadas en 1953 en la colección Crimen, estas novelas casi no han recibido atención. Este trabajo se propone mostrar que estos textos adelantan aspectos fundamentales de la narrativa de Viñas, así como de sus guiones para el cine. Asimismo, estos relatos son significativos desde la perspectiva de la historia del policial argentino. En contraste con la historización llevada a cabo por Walsh ese año (1953), que pone en el centro el relato de enigma, las novelas de la colección Crimen proponen una tradición diferente, que atiende menos al misterio y la solución deductiva que a la biografía criminal y sus determinaciones sociales.

Palabras clave: Pedro Pago, literatura policial, David Viñas, contorno.

In his early years as storyteller, David Viñas wrote-under the pseudonym of Pedro Pago-three novels about famous Argentine bandits: Chicho Grande, Chicho Chico and Mate Cocido. Published in 1953 in the collection Crime, these novels have received almost no attention. This paper intends to show that these texts have some fundamental features and elements of Viñas' narrative work and screenplays of the subsequent years. Also, the three stories are significant from the perspective of the history of detective fiction in Argentina. In contrast to the history of the genre elaborated by Walsh the same year (1953), from a point of view that places in the center the classical whodunit story, this collection prove the existence of a different tradition, which pay less attention to the mystery and deductive resolution than to the criminal biography and its social determinations.

Key words: Pedro Pago, detective story, David Viñas, contorno.

\section{INTRODUCCIÓN}

Como se sabe, David Viñas escribió al comienzo de su carrera como narrador tres novelas cortas policiales sobre tres bandidos célebres argentinos: Chicho Grande, Chicho Chico y Mate Cocido. ${ }^{1}$ Estos tres relatos fueron publicados en 1953, dentro

El bandido era denominado, en realidad, Mate Cosido, por una cicatriz cosida que tenía en la cabeza, es decir, en el "mate". Sin embargo, en muchos casos, por ejemplo en la novela corta de Viñas, se lo denomina Mate Cocido, como si el sobrenombre proviniera de la bebida. 
de la colección Crimen dirigida por Enrique Fentanes. Estas novelas de Viñas casi no han recibido atención alguna hasta la fecha. Hasta donde se sabe existe -acaso deberíamos decir existió- un único artículo sobre el tema, titulado "El caso Pedro Pago", escrito por Faustino Tejedor hacia 1974. Tal texto estaba incluido en un volumen colectivo -Mirta Abbondanza et al., Narrativa policial en la Argentina (1974)-, que hoy resulta imposible hallar. ${ }^{2}$ De este modo, los únicos documentos hoy accesibles sobre estas novelas policiales son las pocas frases del texto de Tejedor referidas en Asesinos de papel, así como algunas frases del propio Viñas incluidas en David Viñas: En busca de una síntesis de la historia argentina, de Estela Valverde, ${ }^{3}$ y la reciente nota de Osvaldo Aguirre sobre estas novelas aparecida en $\tilde{N}$. Revista de cultura el día 16 de noviembre de 2011. ${ }^{4}$

En lo poco que nos ha quedado del texto de Faustino Tejedor, el autor sostiene que la novela Mate Cocido es la mejor de las novelas policiales aparecidas en la colección (Lafforgue y Rivera 1996: 35), mientras que Aguirre no vacila en afirmar que el "texto más logrado del conjunto es Chicho Chico".

Los diálogos, las descripciones y los personajes están más sueltos, desligados de la anécdota, como si Viñas/Pago se hubiera atrevido finalmente a escribir literatura. El capítulo inicial, con la reconstrucción del ambiente del hipódromo de Palermo y una notable escena en que Chicho Chico azota con una fusta a un jockey, no hubieran desentonado en la antología de Walsh. Además el relato no es lineal sino que se

\footnotetext{
El texto aparece relevado en al menos dos estudios sobre el género policial en la Argentina, el célebre Asesinos de papel, en sus ediciones de 1977 (Buenos Aires: Calicanto) y 1996 (Buenos Aires: Colihue), de Jorge Lafforgue y Jorge B. Rivera, y en La ley y el crimen. Usos del relato policial en la Argentina (1880-2000), de Sonia Mattalia (Madrid/Frankfurt am Main: Iberoamerincana/Vervuert, 2008). También Erna Pfeiffer menciona esta obra en una bibliografía para un seminario dictado durante el semestre de invierno de 2010-2011 en la Universidad de Graz. Sin embargo, únicamente los autores de Asesinos de papel dan cuenta de haber accedido directamente al texto de Tejedor. Luego de la muerte de Jorge B. Rivera el texto parece hoy irrecuperable y el propio Jorge Lafforgue -a quien agradecemos enormemente las prontas respuestas a nuestras consultas- nos informa que lo más probable es que este texto se perdiera al ser descuartizada la biblioteca de Rivera. La monografía no conoció una edición más que casera: la cita de Asesinos de papel de 1996 aclara que se trata de una mimeografía y la edición de 1977 explica que el texto es una "extensa, informada y muy despareja monografía realizada hacia 1974 para la Facultad de Filosofía y Letras de la Universidad de Buenos Aires por Mirta Abbondanza, Luis Carlos Edelman, María Esther Díaz, Lucía Fortunato, María de del Rosario López, María E. Pelliza y Guillermo Saccomano” (Lafforgue y Rivera 1977: 32).
}

3 Cf.: "En los últimos años del peronismo yo hice unas novelas infernales que no son nada infernales, pero con las que vivía con el seudónimo de Pedro Pago. Esto creo que no lo sabe nadie. Eran novelas policiales, novelas policiales argentinas, con personajes argentinos y firmaba Pedro Pago. Como su nombre indica era la exaltación del paguismo, de todo eso. Eran unas novelitas que se vendían en quioscos, que se vendían en cantidad, porque era la primera colección policial de quiosco donde se tomaban temas argentinos [...] Funcionaron muy bien. Eso es mérito a atribuirle al editor, que era un personaje fenomenal. Esos años fueron duros, porque era la época en que nació la nena. Ya te digo: pagaban -que era un elemento a tener en cuenta, si no hay cosas que no se entienden-producción, tickets y demás folletines. Creo que pagaban entonces por cada una algo así como cuatro mil pesos, lo que era mucha plata. Eran cocinadas... pero todas con un ambiente argentino.” (Valverde 1989: 67).

4 Recientemente la Biblioteca Nacional acaba de publicar una compilación de estos relatos: Pedro Pago (David Viñas), Policiales por encargo. Buenos Aires: Biblioteca Nacional, 2012. No podemos sino celebrar este emprendimiento, tanto más en un momento en que la muerte de Viñas propicia una revisión de su obra. Sin embargo, nuestro texto omite una discusión detallada de esta edición y del estudio preliminar de Marcos Zangrandi, ya que este artículo fue redactado antes de que apareciera esa nueva edición. Cabe indicar, sin embargo, que Zangrandi considera a estas novelas cortas significativas desde el punto de vista de la biografía intelectual de Viñas y en función de la serie de la cultura popular contemporánea (ibid.: 14-15), y les reconoce un escaso valor literario. Al preguntarse por las “razones” posibles para una lectura de estas novelas, no encuentra razones sino “excusas” (Zangrandi 2012: 15). En contraste con esta perspectiva, nuestro trabajo intenta exhibir el valor literario e histórico-literario de estos textos. 
despliega en forma discontinua y fragmentaria, en episodios y locaciones que sitúan los hechos decisivos (el asalto a una fábrica, el secuestro de un niño, el secuestro fallido de un millonario, la muerte de Chicho Chico) (Aguirre 2011).

Escrito para la prensa diaria, el excelente texto de Aguirre $^{5}$ no puede detenerse en argumentaciones más dilatadas. Sobre el carácter no lineal, fragmentario, episódico de Chicho Chico, cabe indicar que es un rasgo común a los tres relatos, que narran una biografía a partir de determinados episodios significativos, tal como sucede también en las narraciones de Borges que conforman Historia universal de la infamia (1935). De hecho, los tres textos relatan una serie de crímenes protagonizados por el delincuente célebre, y la muerte final de este (Chicho Grande y Chicho Chico) o su desaparición en la selva (Mate Cocido). En relación con la escena de violencia referida por Aguirre, aquella en que Ágata Galiffi castiga a su padre (Chicho Grande) no es inferior en nada a aquella en que Chicho castiga a Gamas (Chicho Chico). Y a diferencia de los dos estudiosos citados, entiendo que el texto más logrado y más promisorio es Chicho Grande, aquel que contiene in nuce los elementos centrales de la poética narrativa de Viñas: aquí encontramos una marcada continuidad con algunos elementos de la serie negra, con la tradición de la novela criminal y, fundamentalmente, con el cine de gangsters y el noir (con especial atención a las relaciones de dominación y sumisión). De las tres novelas cortas, es -por eso- la más influyente en la formación de Viñas como narrador, la más determinante para su literatura inmediatamente posterior, si bien los tres textos adelantan aspectos fundamentales de su obra narrativa (novelas y cuentos) así como de los guiones escritos por Viñas para el cine, y principalmente los vínculos entre literatura y cine (cruciales en la literatura de Viñas).

Asimismo, los tres relatos son significativos desde la perspectiva de la historia de la literatura policial argentina. Publicados en 1953, año en que Walsh inaugura la historiografía del policial en la Argentina, a partir de una serie que pone en el centro el relato de enigma y la tradición del policial en lengua inglesa (Cfr. Setton 2012: 15-34), las novelas de la colección Crimen buscan establecer una serie diferente dentro del ámbito de la literatura policial/criminal argentina, que atiende menos al enigma y la resolución deductiva del acertijo que a la biografía del criminal y sus determinaciones sociales.

Sin embargo, antes de detenernos en este punto, querría indicar tres elementos complementarios y solidarios en Chicho Grande, que distinguen a este relato de las otras dos biografías ficcionales:

A) Chicho grande es -siguiendo la distinción de Genette (1972) en Figures III"mimesis de palabras", mientras que las otras dos novelas cortas son "mimesis de hechos” (esto debería ser un punto fundamental cuando se consideran textos cuyo argumento y personajes provienen presuntamente de biografías célebres, es decir, cuando se supone que la trama de los relatos está tomada de la historia); en Chicho Grande se reproduce el relato de Fraga sobre los hechos, y la voz de este personaje es precisamente eso, la voz de un personaje que reproduce en la conversación los hechos de los que formó parte años atrás. Esto obliga a Viñas/Pago, más allá de la

Tampoco Aguirre ni Eduardo Romano -quien en ese entonces era profesor adjunto de la materia que incluyó en su programa la mencionada monografía- conocen algún modo de dar con el texto. 
significación del pago y del paguismo en el desarrollo de estos relatos (cuestión que trataremos más adelante), a un trabajo con la lengua en la totalidad del relato.

B) De este modo, todos los acontecimientos son narrados desde la perspectiva lateral de Fraga, el chofer de la banda.

C) Por si esto fuera poco, hay en este texto una puesta en escena del autor seudónimo. Precisamente, Pedro Pago es el otro personaje que participa de la conversación, quien escucha el relato de boca de uno de los participantes directos de los acontecimientos (otro elemento que recuerda los comienzos narrativos de Borges en Historia universal de la infamia). ${ }^{6}$

2. Los policiales y el deSARRollo de Viñas COMO NARRAdor EN LA DÉCADA DE 1950 Y COMIENZOS DE LA DÉCADA DE 1960

El mundo criminal que Pedro Pago representa en estas biografías adelanta en buena medida muchos de los motivos que aparecerán luego en la novelas y cuentos publicados bajo el nombre de David Viñas (Cayó sobre su rostro, 1955; Los años despiadados, 1956; Un dios cotidiano, 1957; Los dueños de la tierra, 1959; Dar la cara, 1962; Las malas costumbres, 1963), así como en los guiones que Viñas escribió para las películas de Fernando Ayala -El jefe (1958), El candidato (1959)y de José A. Martínez Suárez -Dar la cara (1962)-. Asimismo, los textos policiales parecen en parte guiones en estado primitivo y presentan casi más elementos propios de la tradición cinematográfica que características de los policiales literarios: si bien se pueden advertir en estos cuentos muchos elementos de la denominada serie negra, los policiales “duros" -también llamados hard-boiled ${ }^{7}$, resultan más numerosos y más fácilmente perceptibles las afinidades con la tradición del film noir y las películas de gangsters: la insistencia en la familia, en la traición, en las relaciones de poder, sus humillaciones y sumisiones. El cine aparece en estos textos, además, como una referencia frecuente, ${ }^{8}$ y se puede advertir en ellos determinadas características formales vinculadas con la tradición cinematográfica: diálogos mordaces, elipsis de amplitud indefinida, montaje paralelo de acciones y enfrentamientos armados en los finales de los relatos, pasajes melodramáticos de amor hollywoodense (por ejemplo, la escena entre Zamacola y la joven secuestrada en Mate Cocido) y pasajes eróticos no menos hollywoodense (las escenas entre Chicho Chico y Ágata), etcétera.

\footnotetext{
Tal como sucede con Rosendo Juárez en “Hombre de la esquina rosada”, también Chicho Grande es un “valiente de labios para afuera” (Chicho Grande 11).

En líneas generales, puede afirmarse que existió una cierta afinidad entre Contorno y la vertiente negra de la literatura policial: “Alrededor de esa misma fecha [ca. 1960], una defensa frontal de la novela 'dura' es asumida por algunos colaboradores inmediatos de la revista Contorno; en particular por Juan José Sebreli, fervoroso exégeta del autor de Cosecha roja [...] Otros contornistas tampoco desdeñaron el género: David Viñas [...] o Carlos Correas” (Lafforgue y Rivera 1996: 23). Asimismo, en la literatura temprana de Viñas se puede advertir también un diálogo consciente con esta tradición: por ejemplo, en el gusto por las novelas de Mickey Spillane del teniente Galli (Viñas 1963: 158).

8 Cf.: "Todo lo que siguió fue muy rápido, como esas películas viejas donde los movimientos de los actores eran velocísimos, sí, señor, como si se hubieran enloquecido de repente” (Chicho Grande 24); “Solamente veía los movimientos como en una película muda. No oía ninguna palabra, ningún ruido; solamente veía toda esa escena patética que se desarrollaba en aquel negocio de la calle Trelles” (Chicho Grande 13).
} 
Los tres relatos tienen por títulos tres nombres célebres de jefes de bandas criminales -y por protagonistas cuatro jefes, como veremos más adelante-, y las funciones de los jefes y los candidatos son centrales para la comprensión de este mundo diegético. Al igual que Un dios cotidiano o Cayó sobre su rostro, estos relatos tienen en su centro los vínculos de conducción y sumisión, y tal como sucede en las películas de Viñas-Ayala, estas relaciones se despliegan a partir de la existencia de una empresa colectiva. En El jefe se trata de una empresa colectiva criminal, en El candidato, en cambio, de una empresa colectiva política: en realidad, en ambos casos se trata de una empresa criminal y política.

Por los temas tratados, por las diferentes aproximaciones a esos temas, las tres novelas policiales tempranas pueden ser vistas, entonces, como los años de aprendizaje de Viñas, pues en conjunto indagan las relaciones de dominación, traición, sumisión, así como los vínculos familiares y en particular las relaciones entre las generaciones (padres e hijos), que serán motivos centrales en las películas mencionadas y en sus primeros intentos novelescos (el vínculo complejo entre Ferré y su padre en Un dios cotidiano; entre Mariano Carbó y su padre en Dar la cara) y cuentísticos (la dominación, la sumisión y la humillación como motivos centrales de muchos de los cuentos de Las malas costumbres ["Un solo cuerpo mudo”; “¡Viva la patria! (aunque yo perezca)” o "Tanda de repuesto”]). Asimismo, tal como sucede en Chicho Grande, también en Dar la cara encontramos una puesta en escena de la figura autoral, en este caso David Viñas:

Próximo estreno en esta sala: El Jefe. Dirección de Fernando Ayala y libro de David Viñas, leía Bernardo con aire aburrido. "David Viñas”. Él lo había conocido: los bigotes excesivos, un poco ridículos. Alguna vez había pensado que se las tiraba de mazorquero para disimular su origen judío. “Medio judío”. Judío a medias, mazorquero a medias [...] Viñas, sí, siguió Bernardo, uno de esos veteranos que siempre daban la lata con lo del 45 esto y lo del 45 aquello. Bueno, hicieron lo suyo. Es decir, se habían hecho romper la cabeza para no comprender nada durante diez años. 1945-1955: diez años repitiendo lo mismo, inflándolo a un Mayor que escribía sobre filosofía y a una colección de viejos liberales que creían en la República española, el poeta Alberti y Haya de la Torre. "Pobres”. Próximo estreno en esta sala. David Viñas y los héroes del 45 (Viñas 1965: 105-106).

Como anticipamos, las tres biografías criminales ${ }^{9}$ presentan una cantidad de motivos comunes vinculados en lo formal y en lo temático con la literatura viñesca de las décadas de 1950 y 1960: relatan en pocas páginas una biografía, lo hacen a partir de episodios seleccionados y terminan invariablemente con una muerte, Chicho Grande y Chicho Chico con la muerte del héroe, Mate Cocido, con la muerte del compañero del héroe, Zamacola. ${ }^{10}$ La relación homoerótica entre Mate Cocido y

Cabe aclarar que estos relatos -al menos Chicho Grande y Chicho Chico; el caso de Mate Cocido es más dudoso- no pertenecen a la literatura de los grandes delincuentes, en que los bandidos representan -tal como Gramsci caracteriza a esta litteratura- la “'vera' giustizia” (1991: 136).

10 "Zamacola había sido su único gran compañero y ahora había quedado ahí tirado como una vieja osamenta bajo el cielo. Mañana lo comerían las alimañas. Mañana. Ahora tenía que hacer un último esfuerzo para perderse en ese monte intrincado que había sido su otro fiel compañero. Ya no se acordaba ni de la joven ni del rescate. Solamente pensaba en escapar y en hundirse para siempre en la selva. En esa selva de la que no saldría jamás. Que lo tragaría como por ensalmo y que lo cubriría para siempre" (Mate Cocido: 123). 
Zamacola también es un motivo que anticipa la narrativa temprana de David Viñas, tal como puede percibirse en las novelas Dar la cara (con una presencia mucho menor en la película) y Los años despiadados, y en cuentos como "¡Viva la patria! (aunque yo perezca)", etcétera. ${ }^{11}$ En las tres novelas cortas, asistimos a una serie de crímenes perpetrados por los protagonistas, en todas hay un secuestro y algún género de traición, en todas alguna escena sexual interrumpida, vinculada con el secuestro respectivo. Estos dos crímenes específicos -secuestro y violación- le dan lugar a Pago/Viñas para adentrarse en las relaciones de uso y de dominio de los cuerpos, en relaciones absolutamente utilitarias tanto en lo afectivo-espiritual como en lo crasamente corporal. Los dos últimos relatos forman de algún modo una unidad, ya que relatan conjuntamente la historia de Chicho Grande, su hija Ágata y su esposo Chicho Chico. Torre Nilsson reelaborará posteriormente estas biografías en La maffia (1972), con detalles que revelan de manera inequívoca el conocimiento del director de las versiones de Viñas (en cuanto al argumento, la película sigue más las novelas cortas de Pago/Viñas que las biografías de estos criminales célebres).

De estas dos historias de Viñas/Pago surge enorme el personaje de Ágata, probablemente el más jefe de los jefes ${ }^{12}$-el más capo, pero a la vez la masca-pito (según la fórmula que hiciera famosa el Negro Pablo en Okupas)-. Tal como sucede con el mundo narrativo de la mafia y en gran medida con el del noir, los ámbitos de estos relatos se presentan como espacios cerrados, que conducen a los hombres a la muerte (también el pueblo de Antonio Vera en Cayó sobre su rostro, el colegio de Un dios cotidiano y las tierras patagónicas en Los dueños de la tierra se presentan como mundos cerrados, etc.). En Mate Cocido, en cambio, el mundo del delito participa de un contexto mayor, y la carrera criminal del héroe -principalmente su comienzoestá determinada en gran medida por las injusticias que sufre siendo un trabajador honrado. En ese sentido, Mate Cocido pertenece a una tradición ligeramente diversa que la implícita en las otras dos novelas cortas: continúa la serie de los personajes perseguidos injustamente por la ley, integrada por Fierro y Moreira, una tradición en que la biografía -y especialmente los condicionamientos sociales y las inequidades del Estado- se presenta como determinante para la formación criminal. Se trata, en este sentido, menos de narraciones policiales que de novelas criminales, que funcionan en cierto sentido como Anti-Bildungsromane o novelas de deformación.

Los héroes de estos tres relatos representan asimismo tipos diferentes de jefes. En el caso de Chicho Grande, estamos ante un jefe comparable en buena medida al personaje de Berger (interpretado por Alberto de Mendoza) en El jefe, un miserable, abusivo y, en última instancia, un flojo. ${ }^{13}$ Sin embargo, este personaje es quizá más

11 En relación con la representación viñesca de la homosexualidad, resulta elocuente la siguiente indicación de Emilio Bernini: "Viñas encuentra en la homosexualidad una forma singular de una microfísica del poder. No la concibe en los términos en que la cultura gay impuso su consideración, por lo menos a partir de los años '80, como una relación igualitaria, identitaria, normalizada y normativa, sino, por el contrario, a partir de los vínculos que induce a establecer cuando aún es, sobre todo, una práctica antisocial y marginal. [...] Se trata de una idea, en parte sartreana, de homosexualidad 'maldita'” (Bernini 2010: 142).

12 Cf.: "Hasta este momento, el que había aparecido como jefe indiscutido era Chicho, pero los acontecimientos me demostraron que no era precisamente él quien resolvía en última instancia todas las cuestiones de la mafia" (Chicho Grande: 21)

13 Este término era bastante recurrente en las películas argentinas de la época: se utilizaba de manera despectiva para designar tanto a los jóvenes que no tenían un trabajo estable como a los adultos - por lo general, padres- fracasados 
cercano al Antonio Vera de Cayó sobre su rostro. Así como Chicho Grande intenta violar a Elena, una muchacha de familia bien que han secuestrado, Antonio persigue a Teresa e insiste en que sea ella la que le lleve la plata adeudada a la oficina. Estamos ante dos jefes viejos, en decadencia, que buscan servirse de su poder para intentar violentar sexualmente a una joven:

$-\dot{¿} Y$ Teresa me va a llevar eso, no? -gangoseó casi.

-Sí, don Antonio.

-¿O tenés miedo que me la pase al cuarto?...

- No, don Antonio, no.

-¿Entonces va Teresa? (Viñas 1975: 13-14)

En términos generales uno puede considerar que Chicho Grande, la última de las novelas criminales, anuncia en gran medida Cayó sobre su rostro, la primera novela firmada por Viñas (publicada dos años después). Y habría que ser demasiado perspicaz para pensar que Cachilo -el perro que sale de la casa y se pone a ladrar cuando llegan Ágata y Chicho Chico, justo antes de la frustrada violación (Chicho grande 23)- no anticipa a Cachilo, el perro que sale de la casa y se pone a ladrar cuando llega don Antonio, justo antes de sus insinuaciones respecto de la posible violación a Teresa (Cayó sobre su rostro 9-10). ${ }^{14}$ En ambos casos, la respuesta a estos intentos de abuso es el castigo de un hijo al viejo: en Cayó sobre su rostro el hijo de Teresa, que grita que no va a permitir que Antonio meta a su madre en la casa y termina arrojando a Antonio Vera del caballo (Viñas 1975: 14); en Chicho Grande, Ágata, quien castiga a su padre hasta cansarse:

Abrió [Ágata] la puerta de un golpe y lo vio a Chicho Grande al lado de la cama donde estaba la muchacha raptada. Él estaba congestionado y ella tenía los ojos cubiertos de lágrimas. El jefe se quedó con los brazos rígidos, como si esperara que alguna cosa cayera del techo y tardara en descolgarse. [...] Ágata lo agarró de la ropa y lo sacudió como un pelele descuajeringado, como si a su padre de pronto se le hubieran quebrado todos los huesos:

- ¡Porquería! -gritaba-, iporquería!, iporquería!

El padre se dejaba zamarrear con calma, casi como si le hubiera pedido que lo hiciera, como si estuviera satisfecho de lo que hacía su hija.

La muchacha los miraba desde la cama: había encogido las piernas y se había arrinconado contra la pared.

-¡Viejo de porquería! -repetía Ágata-, ¡sos un viejo de porquería!

El padre trató como con desgano de zafarse de su hija. Entonces ella lo cacheteó hasta cansarse, hasta que no pudo más. Una vez y otra y otra.

-¡Porquería! -repetía siempre-, ¡porquería! ¡Si hacés eso, vamos a tener un lío, viejo idiota! ¡Viejo idiota! (Chicho Grande 24-25).

y vencidos, que ya no aspiraban al éxito en ninguna de sus formas (política, económica, etc.).

14 En la segunda novela de Viñas, Los años despiadados, la violación de Rube también desempeña un papel fundamental, en este caso en estrecha relación con el ámbito político; en Dar la cara, en cambio, encontramos la violación de Mariano Carbó -suprimida en la película-. También Un dios cotidiano presenta una suerte de violación desplazada (o, al menos, un acto de violencia sexual): nos referimos al episodio en que Bruno le muestra el miembro a Ferré y éste lo golpea brutalmente. 
En un texto reciente, Emilio Bernini (2010: 133-134) ha indicado el carácter realista, balzaciano, político, totalizador y no subjetivo de los relatos de Viñas para el cine; tal rasgo puede extenderse asimismo a su narrativa temprana y a estas tres novelas cortas criminales. ${ }^{15}$ Muchas veces se ha indicado que la novela negra o criminal se diferencia de la novela de enigma o novela problema por el hecho de que la última representa la realidad de manera alegórica, formal; ${ }^{16}$ mientras que la primera aspira a representar la realidad también en su contenido. En este sentido, bien puede pensarse que los relatos de la serie negra tienen ese espíritu totalizador, realista, que no pocas veces ha sido indicado como característica distintiva del cine noir. Se trata de un mundo cerrado, gobernado por la corrupción y por la traición, que se condice en gran medida con los Estados Unidos de la época de la Prohibición: desde esta perspectiva, la pequeña ciudad de Personville (Cosecha roja) -llamada por sus habitantes Poisonville- puede ser vista como la cifra de ese mundo contemporáneo. Esta misma idea es aplicable a estas novelas cortas de Viñas, y en los modelos de jefes que presentan pueden verse los diferentes modos de relaciones verticales. Los dos guiones escritos por Viñas y dirigidos por Ayala funcionan en muchos sentidos como un díptico que representa, a partir de la perspectiva complementaria de ambas películas, el modo de ver la política contemporánea de David Viñas. En primer lugar, El jefe despliega metafóricamente las relaciones verticales y de sujeción propias de la política en un film que, en el contexto de su aparición, debe referir casi necesariamente al peronismo. El candidato, por el contrario, pone a la vista el mundo de los “correligionarios”, tal como se tratan entre sí los políticos que se oponen al partido que tiene por candidato a Bazán, que en el grito de la multitud se confunde con el grito de "Perón, Perón”. Como fue señalado en relación con El jefe, a Viñas no le interesa "la imposición de la ley sino el grupo mismo como patota" (Bernini 2010: 133). Esta patota y el estudio detenido de la patota y de sus formas de vinculación, sometimiento, humillación -en síntesis: el titeo- fueron abordadas por Viñas por primera vez en estos relatos. En las narraciones sobre los jefes de la mafia argentina, nunca nos encontramos con la representación de la ley tal como se da en la novela problema, como el castigo a quien la incumple; en Mate Cocido, en cambio, el relato termina justo en el momento en que aparece la ley. Con detenimiento y detalle, se representa, en cambio, el castigo y el ajusticiamiento dentro del mundo criminal: el asesinato del hijo de Ágata por parte del Lungo (Chicho Grande), la venganza de Chicho Grande que se cobra la vida del Lungo, perdiendo él mismo la vida; el asesinato de Chicho Chico por parte de Gamas al final de Chicho Chico -y

Cabe indicar, sin embargo, una diferencia muy significativa respecto de sus novelas tempranas, sus cuentos y sus guiones para el cine: estas tres novelas cortas prescinden casi por completo de referencias históricas y políticas locales, completamente determinantes en Cayó sobre su rostro (la formación del Estado argentino y la presidencia de Julio Argentino Roca), Los años despiadados y Las malas costumbres (en ambos casos, el peronismo), La semana trágica, etcétera. Por el contrario, encontramos referencias a acontecimientos relevantes de política internacional, en particular remisiones a las dos guerras mundiales.

16 Roger Caillois ha subrayado el carácter esquemático y “esquelético” de la literatura policial de enigma, su alejamiento de la pintura de la vida y de las pasiones, y su aproximación al planteo (y la resolución) de un problema matemático (1990: 179). En este mismo sentido se expresa Bertolt Brecht, quien indica el carácter esquemático de la novela policial, que -afirma - tiene por objeto el pensar lógico y se aproxima al crucigrama (1971: 315-321). La índole unilateralmente lógica de la novela policial de enigma "pura”, en su carácter de puzzle y de acertijo alejado de la vida, llevó a Edmund Wilson a criticar duramente el género como tal. Cfr.: "Who Cares Who Killed Roger Ackroyd?” y “Why Do People Read Detective Stories?” (2007: 657-661 y 677-683, respectivamente). 
que promete una futura venganza de Ágata- y que es un ajuste de cuentas por las humillaciones sufridas por Gamas en otro ajuste de cuentas, etcétera.

Al hablar del paguismo, Viñas indica que las novelas deben ser comprendidas con "todo" lo que significa el paguismo: hasta ahora el paguismo ha sido interpretado solamente en relación con la paga, con el trabajo por la remuneración. Ese "todo" sugiere también otras acepciones. Al igual que Borges en su Historia universal de la infamia, Viñas dice narrar acontecimientos verídicos e intenta negar el carácter literario de sus textos:

Todos los datos referentes a la vida de Chicho Chico los he obtenido en archivos de distintos diarios y en frecuentes consultas en la Biblioteca Nacional, donde están las colecciones completas de las revistas con material gráfico de esa época. Algunos detalles de la intimidad del protagonista se han logrado en entrevistas a distintos personajes vinculados de una manera u otra con esta historia” (Chicho Chico 7).

Viñas, sin embargo, se prueba como narrador en la escritura de estas tres biografías criminales noveladas, y sus historias -ya en el aspecto más llano del argumentotienen más de invención que de realidad. Las muertes de los personajes de Chicho Grande y de Chicho Chico no tienen nada en común con las muertes de sus referentes empíricos; el vínculo familiar entre ellos también ha sido inventado. Viñas deja de lado los criminales e infamias universales, para abocarse solamente a la historia local -del Pago-de la infamia.

\section{OBRAS CITADAS}

\section{Fuentes primarias:}

Pago, Pedro: véase Viñas, David.

Viñas, David. 1953. Chico Chico. Buenos Aires: Editorial Vorágine. 7-52. 1953. Chicho Grande. Buenos Aires: Editorial Vorágine. 7-46. . [1953] 1960. Mate Cocido, El petiso orejudo y Mate cocido. Buenos Aires: Editorial Magazines. 69-123. . [1955] 1975. Cayó sobre su rostro. Buenos Aires: Siglo Veinte. 1956. Los años despiadados. Buenos Aires: Letras Universitarias. [1957] 1996. Un dios cotidiano. Buenos Aires: C.S. Ediciones. [1959] 1976. Los dueños de la tierra. Buenos Aires: Eudeba. [1962] 1965. Dar la cara. Buenos Aires: Jamcana. 1963. Las malas costumbres. Buenos Aires: Jamcana.

2012. Policiales por encargo. Ed. Marcos Zangrandi. Buenos Aires: Biblioteca Nacional.

\section{Fuentes secundarias:}

Aguirre, Osvaldo. 2011. “Los crímenes de juventud” Ñ. Revista de cultura (16 de noviembre). En línea; disponible en: http://www.revistaenie.clarin.com/literatura/David-Viniaspoliciales-Pedro-Pago_0_589741042.html.

Bernini, Emilio. 2010. "Viñas y el cine” El matadero. Revista crítica de literatura argentina 7: 129-143. 
Brecht, Bertolt. 1971. “Über die Popularität des Kriminalromans”. Vogt, J., Der Kriminalroman: Poetik, Theorie, Geschichte 2 vols. Munich: Fink. Vol. 2, 315-321.

Caillois, Roger. 1990. "Le roman policier. Comment l'intelligence se retire du monde pour se consacrer à ses jeux et comment la société introduit ses problèmes dans ceux-ci”. Approches de l'imaginaire. Paris: Gallimard. 177-205.

Genette, Gérard. 1972. Figures III. París: Seuil.

Gramsci, Antonio. 1991. “Sul romanzo poliziesco” Letteratura e vita nazionale. Roma: Editori Riuniti. 136-144.

Lafforgue, Jorge y Jorge B. Rivera. 1977. Asesinos de papel. Buenos Aires: Calicanto. 1996. Asesinos de papel. Buenos Aires: Colihue.

Mattalia, Sonia. 2008. La ley y el crimen. Usos del relato policial en la Argentina (1880-2000). Madrid; Berlín: Iberoamericana; Vervuert.

Setton, Román. 2012. Los orígenes de la narrativa policial en la Argentina: recepción y transformación de modelos genéricos alemanes, franceses e ingleses. Madrid; Berlín: Iberoamericana; Vervuert.

Valverde, Estela. 1989. David Viñas: En busca de una síntesis de la Historia argentina: Buenos Aires: Plus Ultra.

Wilson, Edmund. 2007. “Who Cares Who Killed Roger Ackroyd?” y “Why Do People Read Detective Stories?” Litterary Essays and Reviews of the 1930s \& 40s. Nueva York: The Library of America. 657-661 y 677-683.

Zangrandi, Marcos. 2012. "Estudio preliminary”. En Viñas, David, Policiales por encargo. Buenos Aires: Biblioteca Nacional. 9-31. 